\title{
Influence of distance from traffic sounds on physiological indicators and subjective
}

\author{
evaluation
}

Zhongzhe $\mathrm{LI}^{\mathrm{a}^{*}}$, Jian $\mathrm{KANG}^{\mathrm{b}^{*}}$, Meihui BA ${ }^{\mathrm{a}}$

${ }^{a}$ Key Laboratory of Cold Region Urban and Rural Human Settlement Environment Science and Technology, Ministry of Industry and Information Technology, School of Architecture, Harbin Institute of Technology, Harbin, China.

${ }^{b} U C L$ Institute for Environmental Design and Engineering, University College London (UCL), London, United Kingdom.

"Corresponding author: Zhongzhe LI, lizhongzhehit@gmail.com, School of Architecture, Harbin Institute of Technology, NO.66 Xi Da Zhi Street, Harbin, China; Jian KANG, J.kang@ucl.ac.uk, UCL Institute for Environmental Design and Engineering, The Bartlett, University College London (UCL), London WC1H 0NN, United Kingdom. Tel: +44 (0)20 31087338.

\begin{abstract}
This study examined the influence of different distances of traffic noise and sea sounds on physiological indicators and subjective evaluation. Scene re-creations employed three types of distance: actual close sounds (close to the sound source recorded on site), actual distant sounds (distance attenuation recorded on site) and artificial distant sounds (reduction of the same decibel level across frequencies). Participants displayed higher heart rate, amplitude of the R-wave $(\triangle R)$, heart rate variability, respiration rate, and skin conductance level (SCL) when close to the sound source. Actual distance attenuation affected most subjective evaluation factors (except for Familiarity and Excitement). The $\triangle R$, electroencephalography alpha reactivity, and electroencephalography beta reactivity with actual distant sounds were lower and SCL was higher, relative to those with artificial distant sounds. These findings provide a reference for governments and urban planners when working to improve quality of life in urban areas.
\end{abstract}

Keywords: soundscapes, sound source distance, physiological response, subjective evaluation

\section{Introduction}

Road traffic noise is the most common source of environmental noise and can cause human diseases, such as cardiovascular and cerebrovascular diseases (Seidler et al., 2016), diabetes (Roswall et al., 2018), insomnia (Vallet et al., 1983; Finegold et al., 1994; Miedema and Vos, 1998; Muzet, 2007; Basner et al., 2010) and atrial fibrillation (Monrad et al., 2016). The basic method of controlling traffic noise is to increase the distance between the road and residential buildings. However, due to urbanisation and shortage of land resources, there is rarely enough retreat distance; alternatives in an urban environment 
include controlling traffic speed and changing traffic mode, building noise barriers, and placing sensitive rooms on the quiet side of a building. At present, as a standard to control noise, the traffic noise index still takes the sound pressure level (SPL) as the main assessment indicator (Griffiths and Langdon, 1968), but the spectral characteristics of sound are seldom considered. In the study of acoustics, the attenuation mode can affect the frequency spectrum of sound, influencing the perception of sounds. The spectrum of a sound changes with distance from the sound source, even if the interference of other sound sources or barriers is excluded, because the attenuation rates of high- and low-frequency components differ. This is mainly due to the different sound absorption coefficients of air and ground for different frequencies of sound, the higher the sound frequency, the easier it is for the frequency to be obscured and absorbed, so the high-frequency components are more likely to attenuate. The spectrum also plays an important role in subjective perception (Versfeld and Vos, 1997; Nilsson, 2007; Joynt and Kang, 2010; Hongisto et al., 2018). Different noise control methods lead to different kinds of sound attenuation, which changes the frequency spectrum of sound. Using real recordings from different locations to examine differences in individuals' psychological and physiological responses to sound is worth to study.

The study of soundscape provides a new direction for noise control research by focusing on individuals' perceptions within the acoustic environment, rather than on just the physical characteristics of sound (Kang et al., 2016; Aletta et al., 2016). Soundscape studies pay attention to the classification and evaluation of soundscape attributes. Numerous studies have shown that natural sounds (particularly the sound of water) exerted a masking effect on traffic noise (Watts et al., 2009; Coensel et al., 2011). The results of laboratory experiments showed that fountain sounds reduced the subjective loudness of traffic noise and other subjective evaluation factors, such as levels of annoyance, significantly. These effects were most significant when the SPL of water sounds were three decibels (dB) lower than that of traffic noise; however, low-frequency components, similar to that of road traffic, should be avoided in water sounds, as it alters the masking effect (Jeon et al., 2010; Nilsson et al., 2010; Galbrun and Ali, 2013). Both sea and highway traffic sounds are subjectively experienced as a constant roar; they have a strong similarity in the spectrum (Hunter et al., 2010). In contrast, the sound of sea waves is considered soothing or hypnotic in the field of disease rehabilitation and insomnia treatment (Cerwén et al., 2016). Why do sea and traffic sounds, which have similar acoustic characteristics, produce different results in subjective evaluation? The similarities and differences between the two sounds are worthy of examination with respect to both physiological and psychological factors.

Most laboratory experiments have examined participants' feedback on soundscapes via questionnaires and interviews, and few have collected data using physiological measurements (Erfanian et al., 2019; Torresin et al., 2019). In the existing physiological research examining soundscapes, values for physiological indicators in the human body are usually collected using stimulus-locked designs and passive listening to study changes in those indicators with different types of sound and differences in restoration effects (Bradley et al., 2001; Alvarsson et al., 2010; Irwin et al., 2011; Hume \& Ahtamad, 2013; Li and Kang, 2019). Medvedev et al. (2015) compared the restorative potential of sea and traffic sounds and showed that sound type did not exert a significant effect on changes in heart rate (HR) or skin conductance levels (SCLs), although this experiment revealed that there is a certain relationship between 
subjective evaluation of sound type and physiological response. Hunter et al. (2010) used functional magnetic resonance imaging to examine neural responses to sounds of sea waves and speedways. The results demonstrate that visual context can modulate the connectivity of the auditory cortex with regions implicated in the generation of subjective states. However, at present, physiological research on soundscapes has seldom focused on changes in sound attributes. More research about the perception of spectrum difference between real and artificially attenuated recordings are required in the field of soundscape.

Overall, few studies have analysed the effects of individuals' perceptions of sound environments in terms of the distance of sounds, on physiological indicators. To address this issue, it is necessary to consider traffic and sea sounds under different conditions. Therefore, the purpose of this study was to measure participants' physiological responses and subjective evaluations by re-creating sea and traffic sounds in the laboratory. By comparing the differences in physiological indicators and subjective evaluation factors between actual and artificially attenuated sounds, on the one hand, we can know whether the change of spectrum will affect human perception. On the other hand, from a methodology perspective, we can discuss the difference between the actual recorded sound and the artificially processed sound when reproducing the soundscape in the laboratory. Considering this, we proposed two main research questions: (1) Does the distance of traffic and sea sounds affect physiological indicators? (2) Does the distance of traffic and sea sounds affect individuals' subjective evaluations? The answers to these questions could help to provide policy suggestions for local governments and guidance for experimental methods such as recording and re-creation of sounds in the laboratory.

\section{Method}

A combination of physiological measurements and subjective evaluation was used in the study. Participants were divided into three groups according to different types of distance from sea and traffic sounds (presented randomly), and physiological indicators were monitored using attached detectors. After each sound, participants were asked to complete a questionnaire pertaining to their subjective evaluations of the sounds.

\subsection{Participants}

Participants were 180 unpaid undergraduates and graduate students (98 men and 82 women). Their mean age was 26.29 ( $\mathrm{SD}=3.171$ range: $18-34)$ years. In accordance with previous research, this sample was large enough to pass the power analysis, and the amount of data obtained was sufficient to facilitate a follow-up correlation and dimensionality reduction analysis. Participants had no hearing problems and did not use psychotropic medication. They were required to wear comfortable clothing and, to avoid fatigue, did not perform strenuous exercise during the two hours preceding the experiment. The study was approved by the Degree Committee of the School of Architecture, Harbin Institute of Technology (this governing body includes an ethical review board). Participants' names were not included in the questionnaire, and all participants provided written informed consent to participate in the study. 


\subsection{Stimuli}

To record attenuated sound, two sound sources, one each from the natural and mechanical sound categories, were selected as sound stimuli: sea waves (unpopulated beaches on a calm sunny day) and highway traffic (a sunny afternoon on a suburban expressway) (Axelsson et al., 2010; Hunter et al., 2010; $\mathrm{Ba}$ and Kang, 2019a). There was no interference from other sound sources within $300 \mathrm{~m}$ of the relevant sound sources.

The stimuli were captured using video and audio recording techniques for a variety of reasons: vision and hearing often cooccur, and although the soundscape is mainly dominated by auditory, the context is also very important. Further, multi-sensory interaction allows for a more immersive experience, avoiding scene unrecognition and associations that are inconsistent with the actual scene when listening to sound only. For each sound source, two different sites were selected for recording: close to the sound source (at the edge of the sea waves or road) and far from the sound source (60 $\mathrm{m}$ from the sea waves or $120 \mathrm{~m}$ from the edge of the road). Both scenes represent suburban regions (more than five kilometres from the nearest factory and urban area). The wind speed on the recording days were within $2 \mathrm{~m} / \mathrm{s}$, and there was no considerable interference of human and biological sounds. Given the difference of the sound absorption coefficient between the sand in the sea sites and the ground in the traffic sites, the distant position is different in the two scenes in order to achieve relatively equivalent attenuation conditions. Each sound was recorded for more than five minutes at the two scenes, and a one-minute video clip was recorded as stimulation material for each site.

Sound stimuli are usually played back via binaural or ambisonic audio methods in the laboratory. Although ambisonic audio creates a better sense of immersion for participants, because they can receive a more realistic sound experience by rotating their heads during the experiment (De Gelder and Bertelson, 2003; Hermida Cadena et al., 2017), binaural recording is widely used in the study of physiological indicators because most indicators, such as electroencephalogram (EEG) values, are sensitive and require participants to avoid moving their bodies and heads. Since human beings determine the position of sound based on variances between the input of each ear when receiving sound signals, binaural recording can truly restore the soundscape and provide the experience of immersion. Therefore, in experiments that do not require sound interaction, binaural recording, as a fixed direction recording, is closest to human hearing (Hong et al., 2017). In the current experiment, the dummy heads (Head Acoustics HMS III) were used to record the sounds, and headphones (BHS II) were used in playback. The headphones match the Dummy Head, which simulates the human ear to record the auditory characteristics of the spectrum, and the headphones can realistically play back the recording without calibration. The video stimuli were recorded using GoPros and presented via a TV screen (Samsung H6400: $166.030 \mathrm{~cm} * 93.375 \mathrm{~cm}(75$ inches), resolution: $1920 * 1080 \mathrm{p}$ ).

As shown in Figure 1, in the sea condition, the sound close to the sound source (actual close sound) was recorded at $72.1 \mathrm{~dB}(\mathrm{~A})$ and that far from the sound source (actual distant sound) was recorded at $51.3 \mathrm{~dB}(\mathrm{~A})$, and in the traffic condition, they were recorded at $74.8 \mathrm{~dB}(\mathrm{~A})$ and $56.5 \mathrm{~dB}(\mathrm{~A})$, respectively (Figure 2). The A-weighting equivalent continuous sound levels (LAeqs) of the actual close sounds were 
compressed to create the artificial sound stimuli (artificial distant sound) for both sounds. The LAeqs for the artificial distant sounds were equal to those of the actual distant sounds but had similar spectral characteristics to those of the actual close sounds.

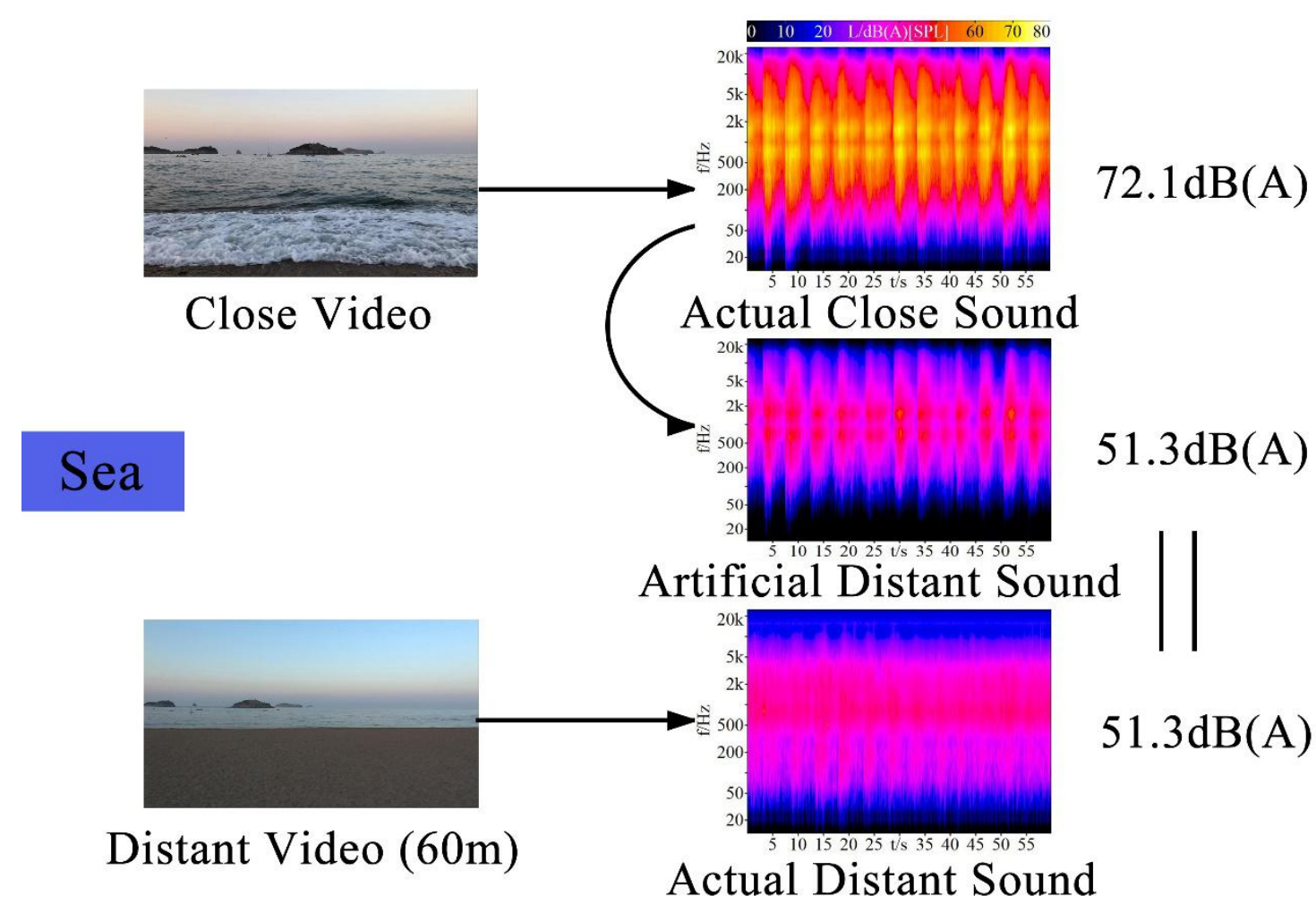

Figure 1 Visual stimuli and sound spectrum of sea sound 


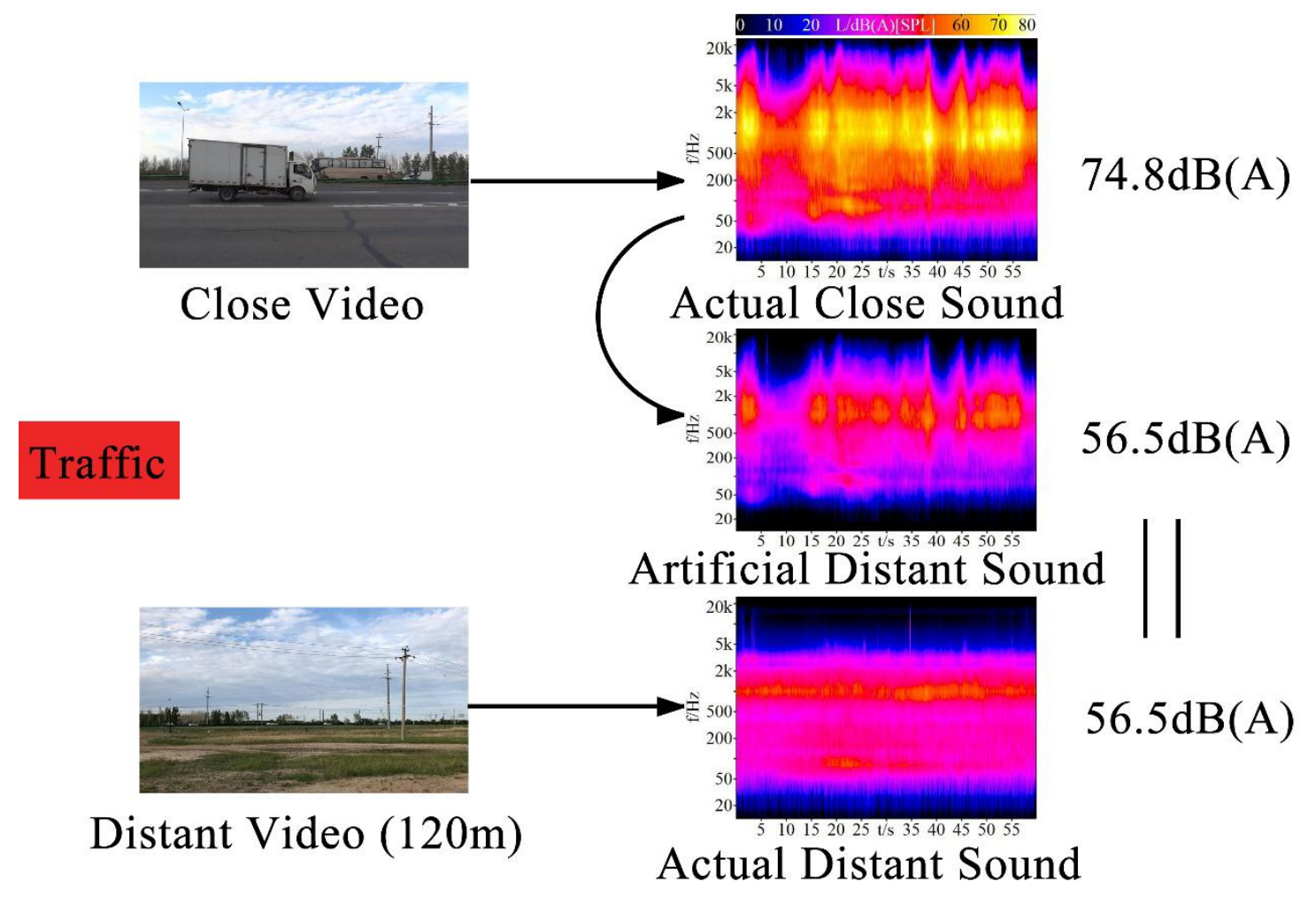

Figure 2 Visual stimuli and sound spectrum of traffic sound

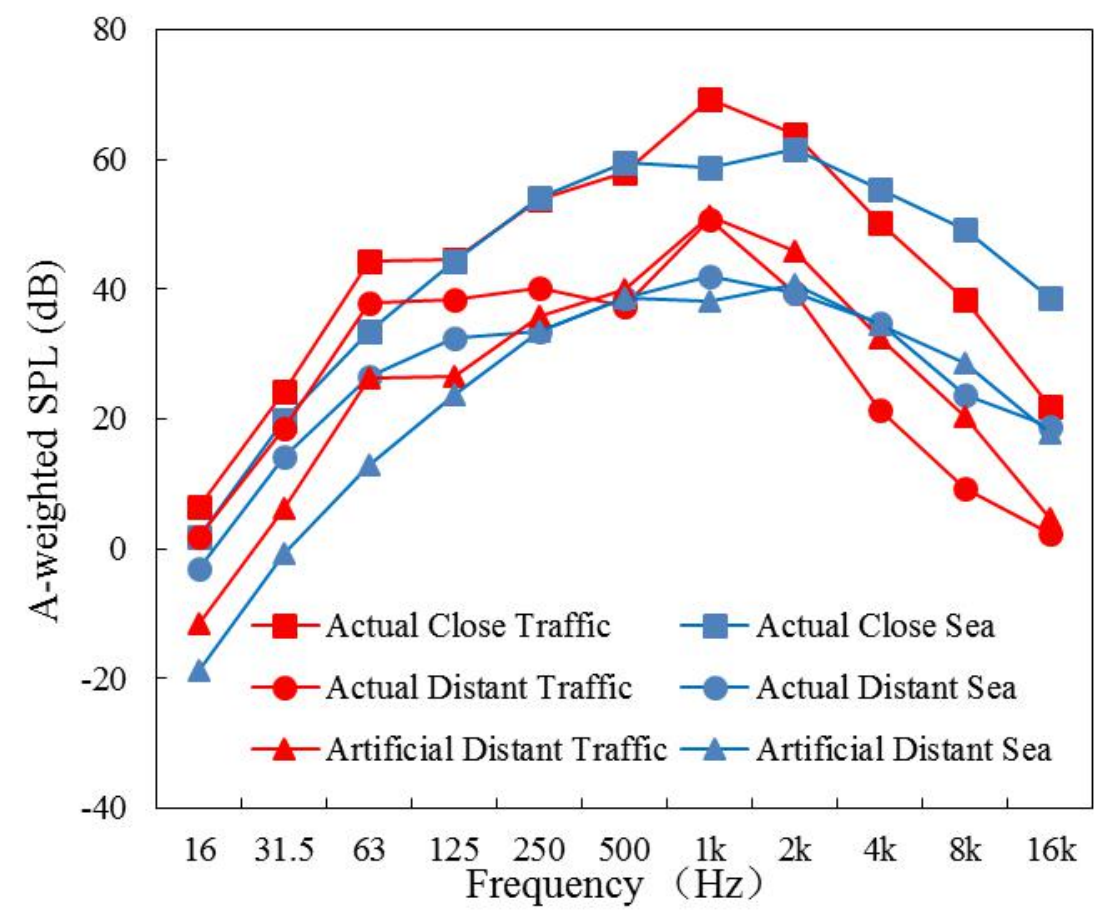

Figure 3 Frequency spectrums of traffic sound and sea sound

As shown in Figure 2, while the overall SPL decreased, the time variability of the actual distant sounds weakened. There was a strong similarity between sea and traffic sounds with respect to frequency 
spectrum values, while the regularity of the sea sound was more obvious relative to that of the traffic sound. For the sea sounds, the regular pattern of the frequency spectrum changed with time, because the regular sound produced by the spray flapping onto the beach and the interval between the waves was about $5 \mathrm{~s}$. For the traffic noise (in which large transport vehicles account for about $40 \%$ of all vehicle density), because the interval between vehicles was random, the traffic noise sounded irregular. As shown in Figure 3, there is little difference in the frequency spectrum of actual close sounds between sea and traffic, mainly reflected in the relatively large low-frequency components of traffic sound. With an increase in distance, high-frequency components decreased and the proportion of low-frequency noises increased for traffic sounds. In addition, although the SPL of artificial distant sounds were equal to actual distant sounds, given that the artificial sounds were compressed by the real sounds at close sites, they sounded closer to the sound source and were more vivid. There was no significant difference in frequency spectrum values for each recording between the left and right ears.

\subsection{Physiological measurements}

Physiological signals were monitored using a BIOPAC MP160 system. The physiological sensors measured included electrocardiogram values (positive and negative poles were alternated between the left and right wrists, while the grounding electrode was attached to the right foot); EEG values (the F7, F8, T3, T4, T5, T6, C3, C4, and Cz electrodes were attached at their proper positions, and the reference electrodes were placed on the participant's left and right earlobes); respiratory waves (the sensor was fixed to the chest through a respiratory band); SCLs (measured on the medial surface of the non-dominant $2 \mathrm{nd} / 3 \mathrm{rd}$ finger); and body surface temperature (measured at the back of the non-dominant hand). The sampling rates of all sensors were $2000 \mathrm{~Hz}$.

Physiological signals were analysed using AcqKnowledge 5.0 software. The 10 physiological indicators measured included $\mathrm{HR}$, amplitude of the R-wave $(\Delta \mathrm{R})$, heart rate variability (SDNN-HRV; calculated using the SDNN (standard deviation of NN intervals) method), high-frequency band in the HRV power spectrum (HF-HRV), EEG alpha reactivity ( $\alpha$-EEG; determined via filtering at the main frequency of 8-13 Hz), EEG beta reactivity ( $\beta$-EEG; determined via filtering at the main frequency of 14-30 Hz), respiration rate (RR; calculated from the peak-to-peak distance of the respiratory wave), respiration depth (RD; calculated from the amplitude of the respiratory wave), SCL, and skin temperature (ST).

The cardiovascular response, respiration and skin electrical signals involved in this experiment are controlled by the autonomic nervous system (ANS) and related to psychological factors such as emotion (Zhao et al.,2018), and the ANS is coordinated by sympathetic and parasympathetic nerves (McCorry, 2007; Kreibig, 2010). Sound as a signal stimulates sympathetic activity generating dynamic homeostasis imbalance, while the parasympathetic nerves are continuously active to maintain balance in human body. $\mathrm{HR}$ is the most frequently reported cardiovascular response variable, followed by HRV and body surface temperature. In the indicators of HRV, the SDNN, as a time-domain parameter, reflects the overall activity of the ANS and can be used to evaluate the regulatory ability of the ANS. HF is a frequency domain indicator, reflecting the activity of parasympathetic nerves. The $\alpha$-EEG appears with relaxation (Klimesch, 
1999; Fachner et al., 2013), while $\beta$-EEG is closely related to behaviour, active, effortful or anxious thinking, and active attention (Fernández et al. 1995; Prinsloo et al., 2013).

\subsection{Subjective evaluations}

Participants were asked to describe the sounds using pairs of comparative words. Existing research has provided a wealth of semantic evaluation indicators, which can be divided into four categories according to different soundscape attributes: satisfaction, strength, fluctuation, and social factors (Kang and Zhang, 2010; Zhang et al., 2018). The questionnaire in this study included 11 pairs of comparative words describing evaluation factors of different dimensions, including Comfort, Harshness, Pleasantness, Loudness, Liking, Familiarity, Strength, Excitement, Eventfulness, Chaos, and Congruency, which can be used to evaluate sounds comprehensively (Ba and Kang, 2019b). We used a 7-point Likert scale (taking Comfort as an example, scores ranged from 1 to $7: 1=$ very uncomfortable, $2=$ uncomfortable, $3=$ a little uncomfortable, $4=$ neither comfortable nor uncomfortable, $5=$ a little comfortable, $6=$ comfortable, $7=$ very comfortable).

\subsection{Procedure}

The participants were randomly divided into three groups (60 in each group). They were required to watch videos, listen to sounds, and imagine themselves in the corresponding real environment. Each group of experiments presented the sounds in different kinds of distance: actual close (actual close sounds + close videos), actual distant (actual distant sounds + distant videos), and artificial distant (artificial distant sounds + distant videos).

The experiment was performed in a soundproof audiometric room with no objects to interfere with attention except the required experimental equipment (Hermida Cadena et al., 2017; Lindquist et al., 2016). Participants were asked to sit comfortably at a distance of $1.5 \mathrm{~m}$ from the screen. The investigator explained the entire experimental procedure. Once participants indicated that they understood and agreed to all the terms, the investigator connected the BIOPAC MP160 system. After the connection process was complete and the physiological signal was calibrated, the E-prime software was initiated. As a commonly used psychological and behavioural software, E-prime can transmit edited audio-visual stimuli to BIOPAC signal modules with millisecond accuracy in the form of digital numbers and time markers.

The experiment started with participants being asked to relax. When the investigator observed a tendency of physiological indicators to stabilise, the investigator left the audiometric room and went to the observation room, and the experiment properly began. The participants were asked to relax fully in the first five minutes. During this period, the subjects would not receive any external stimulation, and their resting states were recorded as baseline for later analysis. The two sounds (sea and traffic) then each appeared once at random (the duration of each sound was one minute). After listening to the first sound, participants subjectively evaluated the sound they had just heard. They were then instructed to relax for $90 \mathrm{~s}$ (considering that extremely long intervals can make subjects feel tired or irritated, the interval time in the experiment was shortened to $90 \mathrm{~s}$ ), listen to the subsequent sound, and subjectively evaluate the second sound. When both sounds had been presented and participants had completed the subjective 
questionnaires, the investigator re-entered the audiometric room, removed the headphones and electrodes, and ended the experiment.

\subsection{Data analysis}

Because of the significant differences between individuals, all physiological indicators were normalised. The data obtained during the first five minutes of the experiment in the resting state were recorded as baseline data, and each physiological dataset was converted into a relative deviation from the baseline value according to the following formula:

Percentage change $(\%)=([$ raw value - baseline value $] /$ baseline value $) * 100$.

Baseline is the benchmark value of the physiological indicators obtained by the subjects without stimulation. The purpose of the above formula is to normalise the data of all people through baseline, so that the data between different people are comparable.

SPSS 25.0 was used to establish a database containing all results. The data were analysed using the following methods: (1) Differences between the physiological indicators measured for different distances and sound type were analysed using an analysis of variance (ANOVA). (2) The ANOVA was used to detect differences in subjective data for different distances and sound type. (3) Correlations between physiological indicators and subjective evaluation factors were analysed. Because the covariance of each index is not equal (Box's test $\mathrm{p}<.01$ ), a multivariate analysis of variance was not carried out.

ANOVAs were performed with the 10 physiological indicators as dependent variables, and distance (actual close, actual distant, and artificial distant) and sound type (sea and traffic) as independent variables, to examine the effects of distance and sound type and the interaction between them (Distance * Sound) on various physiological indicators. Like physiological indicators, the evaluation factors were used as dependent variables, and distance and sound type were included as independent variables to analyse the influence of sound type and distance on subjective evaluations.

As the actual distant group was the control group, and the sample size in each group was the same, the Dunnett test, which is useful for comparing several treatments via a single control, was performed to make a fixed comparison between the actual close and actual distant groups. Similarly, the difference between artificial distant and actual distant groups was tested via Dunnett tests to analyse the effect of artificial distance attenuation on physiological indicators. The processing of subjective evaluation data was like that of physiological indicators.

\section{Results}

\subsection{Effects of distance on physiological indicators}

\subsubsection{ANOVAs examining the effects on physiological indicators}

The results of the ANOVAs with 10 physiological indicators as dependent variables, distance (actual close, actual distant, and artificial distant) and sound type (sea and traffic) as independent variables are shown in Table 1. The estimated marginal means for the cross-terms of the factors in each model are 
Zhongzhe Li, Jian Kang, Meihui Ba: Transportation Research Part D: Transport and Environment [https://doi.org/10.1016/j.trd.2020.102538]

shown in Figure 4.

Table 1 ANOVAs examining differences in the effects of distance and sound type on physiological indicators

\begin{tabular}{|c|c|c|c|c|c|c|}
\hline Indicator & Effect & $\begin{array}{c}\text { Type III Sum of } \\
\text { Square }\end{array}$ & $\mathrm{df}$ & Mean Square & $\mathrm{F}$ & Sig. \\
\hline \multirow{3}{*}{ HR } & Distance & 260.757 & 2 & 130.379 & 5.576 & .004 \\
\hline & Sound Type & 2.388 & 1 & 2.388 & 0.102 & .749 \\
\hline & Distance* Sound & 33.721 & 2 & 16.86 & 0.721 & .487 \\
\hline \multirow{3}{*}{$\Delta \mathrm{R}$} & Distance & 674.25 & 2 & 337.125 & 14.019 & $<.001$ \\
\hline & Sound Type & 1.259 & 1 & 1.259 & 0.052 & .819 \\
\hline & Distance* Sound & 6.472 & 2 & 3.236 & 0.135 & .874 \\
\hline \multirow{3}{*}{ SDNN-HRV } & Distance & $60,527.881$ & 2 & $30,263.941$ & 7.969 & $<.001$ \\
\hline & Sound Type & $2,080.826$ & 1 & 2080.826 & 0.548 & .460 \\
\hline & Distance* Sound & $20,693.121$ & 2 & $10,346.561$ & 2.724 & .067 \\
\hline \multirow{3}{*}{ HF-HRV } & Distance & $1,200.771$ & 2 & 600.385 & 1.48 & .229 \\
\hline & Sound Type & $1,212.604$ & 1 & $1,212.604$ & 2.989 & .085 \\
\hline & Distance* Sound & 474.661 & 2 & 237.33 & 0.585 & .558 \\
\hline \multirow{3}{*}{$\alpha-E E G$} & Distance & $3,797.559$ & 2 & $1,898.78$ & 3.626 & .028 \\
\hline & Sound Type & $10,298.466$ & 1 & $10,298.466$ & 19.666 & $<.001$ \\
\hline & Distance* Sound & 446.382 & 2 & 223.191 & 0.426 & .653 \\
\hline \multirow{3}{*}{$\beta$-EEG } & Distance & $2,775.323$ & 2 & $1,387.661$ & 6.602 & .002 \\
\hline & Sound Type & 856.439 & 1 & 856.439 & 4.075 & .044 \\
\hline & Distance* Sound & 307.491 & 2 & 153.745 & 0.731 & .482 \\
\hline \multirow{3}{*}{ ST } & Distance & 123.865 & 2 & 61.932 & 2.302 & .102 \\
\hline & Sound Type & 23.475 & 1 & 23.475 & 0.873 & .351 \\
\hline & Distance* Sound & 124.21 & 2 & 62.105 & 2.309 & .101 \\
\hline \multirow{3}{*}{$\mathrm{RR}$} & Distance & $4,997.347$ & 2 & $2,498.673$ & 4.775 & .009 \\
\hline & Sound Type & 34.383 & 1 & 34.383 & 0.066 & .798 \\
\hline & Distance* Sound & $1,967.416$ & 2 & 983.708 & 1.88 & .154 \\
\hline \multirow{3}{*}{$\mathrm{RD}$} & Distance & $1,881.000$ & 2 & 940.500 & 1.813 & .165 \\
\hline & Sound Type & $2,215.327$ & 1 & $2,215.327$ & 4.271 & .040 \\
\hline & Distance* Sound & 775.234 & 2 & 387.617 & 0.747 & .474 \\
\hline \multirow{3}{*}{ SCL } & Distance & $47,757.768$ & 2 & $23,878.884$ & 29.692 & $<.001$ \\
\hline & Sound Type & 5839.215 & 1 & $5,839.215$ & 7.261 & .007 \\
\hline & Distance* Sound & $2,686.333$ & 2 & $1,343.166$ & 1.67 & .190 \\
\hline
\end{tabular}




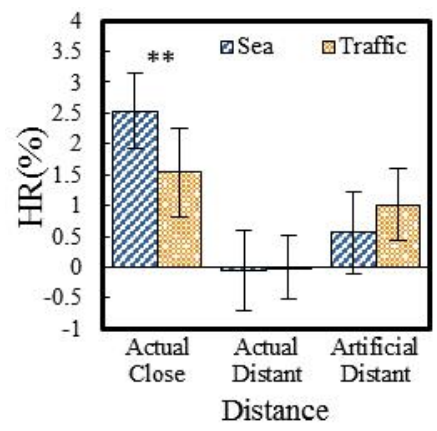

(a) HR

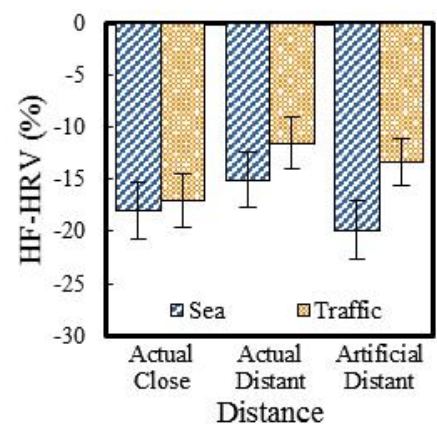

(d) HF-HRV

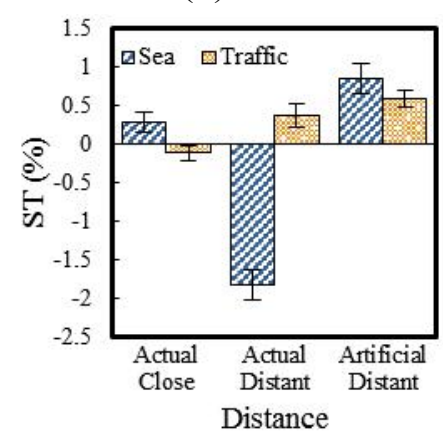

(g) ST

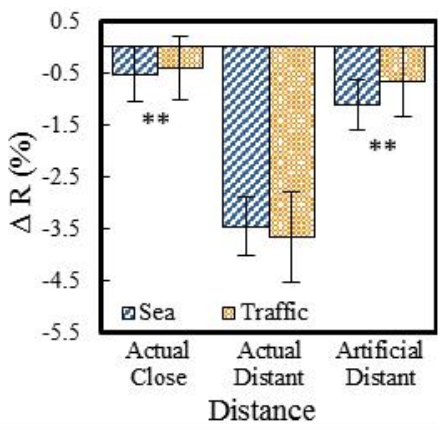

(b) $\Delta \mathrm{R}$

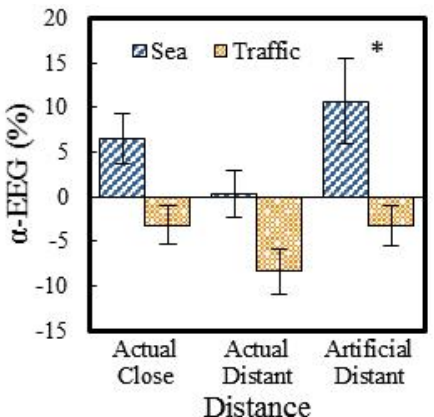

(e) $\alpha$-EEG

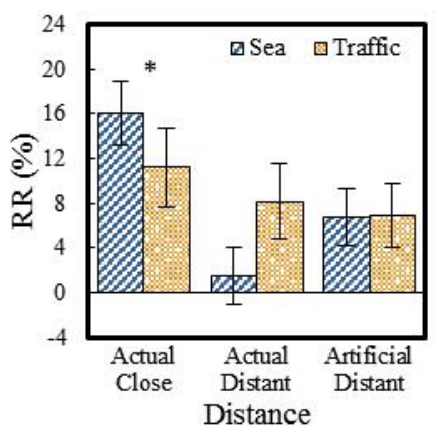

(h) RR

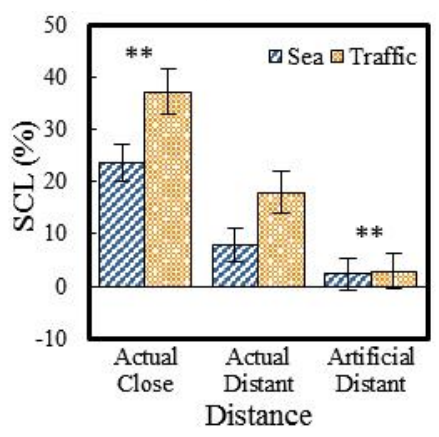

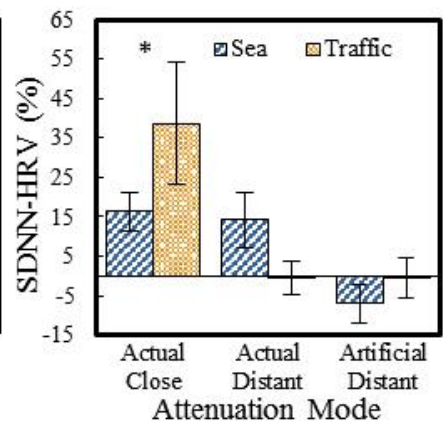

(c) SDNN-HRV

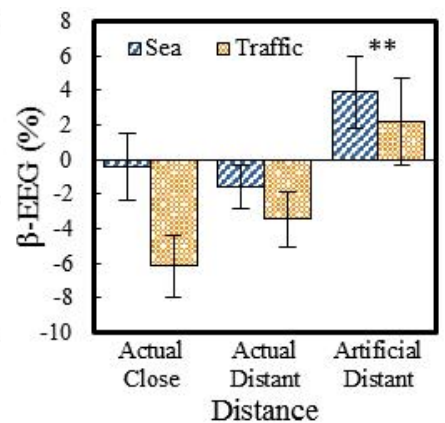

(f) $\beta$-EEG

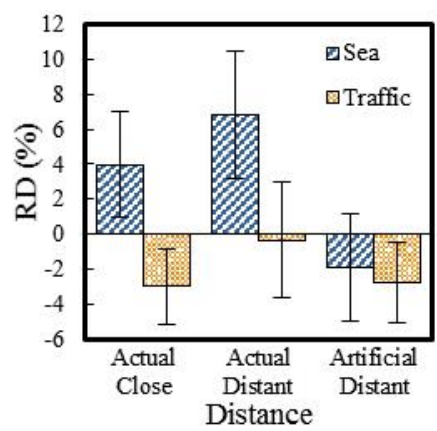

(i) $\mathrm{RD}$

(j) SCL

Figure 4 Changes in physiological indicators according to distance and sound type.

Note: The ordinates represent the percentage of change in each physiological indicator relative to the resting state. Because the change ranges for different physiological indicators differed, the ranges of the ordinate in the diagrams also differ. $* * \mathrm{p}<.01, * \mathrm{p}<.05$

As shown in Table 1, distance exerted effects on HR, $\Delta \mathrm{R}$, SDNN-HRV, $\alpha$-EEG, $\beta$-EEG, RR, and SCL values and sound type influenced $\alpha$-EEG, $\beta$-EEG, RD, and SCL values $(p<.05)$. The effects of the 
interaction between distance and sound type in all indicators were not significant, showing the same trends for sea and traffic.

\subsubsection{Effect of actual distance attenuation of sound on physiological indicators}

Because the ANOVA model can test only whether one factor affects the dependent variable and cannot specify the changing trend in dependent variables at different levels, differences between the actual close and actual distant groups were compared in post-hoc tests to analyse the effects of actual distance attenuation on physiological indicators. The results of the Dunnett tests examining the effect of actual distance attenuation on physiological indicators are shown in Table 2.

Table 2 Dunnett tests examining the difference in physiological indicators between the actual close and actual distant groups

\begin{tabular}{cccccc}
\hline \multirow{2}{*}{ Indicator } & Mean Difference & Std. Error & Sig. & \multicolumn{2}{c}{$95 \%$ Confidence Interval } \\
\cline { 5 - 6 } & $(\%)$ & 0.624 & .002 & 0.683 & 3.456 \\
HR & $2.070^{*}$ & 0.633 & $<.001$ & 1.690 & 4.502 \\
$\Delta \mathrm{R}$ & $3.096^{*}$ & 7.956 & .019 & 2.955 & 38.295 \\
SDNN-HRV & $20.625^{*}$ & 2.980 & .107 & -0.985 & 12.258 \\
$\alpha$-EEG & 5.636 & 1.888 & .889 & -4.958 & 3.431 \\
$\beta$-EEG & -0.763 & 2.978 & .006 & 2.184 & 15.418 \\
RR & $8.801^{*}$ & 3.661 & $<.001$ & 9.405 & 25.667 \\
SCL & $17.536^{*}$ & &
\end{tabular}

Note: The table does not show the indicators that were not affected by distance in Table 1.

Table 2 shows significant differences in HR, $\triangle R$, SDNN-HRV, RR, and SCL values. Specifically, the actual close group showed higher HR, $\triangle \mathrm{R}, \mathrm{SDNN}-\mathrm{HRV}, \mathrm{RR}$, and SCL values relative to those of the actual distant group, indicating that for both sea and traffic sounds, higher SPL led to faster HR, shortness of breath, and increased SCL. Actual distance attenuation exerted an effect on HR and $\Delta \mathrm{R}$ values; the differences between the two groups were only $2.070 \%$ and $3.096 \%$, respectively. In addition, it exerted effects on RR, SCL, and SDNN-HRV values, at $8.801 \%$, $17.536 \%$, and $20.625 \%$, respectively. The change of RR, SCL, and SDNN-HRV is larger than that of HR and $\triangle \mathrm{R}$, this could have occurred because RR, SCL, and SDNN-HRV were more sensitive. Notably, actual distance attenuation did not exert a significant effect on $\alpha$-EEG or $\beta$-EEG values.

\subsubsection{Effect of artificial distance attenuation of sound on physiological indicators}

Similar to the results shown in Section 3.1.2, the results of the Dunnett tests examining the difference in physiological indicators between the artificial distant and actual distant groups are shown in Table 3. 
Table 3 Dunnett tests results for the difference in physiological indicators between the artificial distant and actual distant groups

\begin{tabular}{cccccc}
\hline \multirow{2}{*}{ Indicator } & Mean Difference & Std. Error & Sig. & \multicolumn{2}{c}{$95 \%$ Confidence Interval } \\
\cline { 5 - 6 } & $(\%)$ & 0.624 & .320 & -0.569 & 2.204 \\
HR & 0.817 & 0.633 & $<.001$ & 1.255 & 4.067 \\
$\Delta \mathrm{R}$ & $2.661^{*}$ & 7.956 & .308 & -28.276 & 7.064 \\
SDNN-HRV & -10.606 & 2.980 & .019 & 1.123 & 14.365 \\
$\alpha$-EEG & $7.744^{*}$ & 1.888 & .007 & 1.367 & 9.756 \\
$\beta$-EEG & $5.561^{*}$ & 2.953 & .721 & -4.557 & 8.564 \\
RR & 2.004 & 3.661 & .009 & -18.503 & -2.240 \\
SCL & $-10.372^{*}$ &
\end{tabular}

Note: The table does not show indicators that were unaffected by distance in Table 1.

Table 3 shows that $\Delta$ R, $\alpha$-EEG, and $\beta$-EEG values in the artificial distant group were higher and SCLs were lower relative to those in the actual distant group. The differences between $\triangle \mathrm{R}$ and SCL values was $2.661 \%$ and $-10.372 \%$, the difference of $\Delta \mathrm{R}$ was slightly smaller than $3.096 \%$ in Table 2 , and the change caused by SCL in Table $3(10.372 \%)$ was also smaller than that shown in Table $2(17.536 \%)$, indicating that the influence of artificial distance attenuation (change of spectrum) on $\triangle \mathrm{R}$ and SCL values was weaker relative to that of actual distance attenuation (change of sound source distance). Only the artificial distance attenuation exerted a significant effect on $\alpha$-EEG and $\beta$-EEG values (see Table 3), and actual distance attenuation exerted no effect on these same indicators (see Table 2). This suggests that at the same SPL, people might be more comfortable with artificially attenuated sound ( $\alpha$-EEG increased and SCL decreased, which indicated that people are more relaxed in these scenes). A possible reason was that there were many low-frequency components in the natural attenuated sound, which might cause physical discomfort. It has also been mentioned in other studies (Nilsson, 2007; Jeon et al., 2010) that too much low-frequency in sound may lead to an increase in annoyance.

\subsection{Effects of distance on subjective evaluation factors}

\subsubsection{ANOVAs examining the effects on subjective evaluation factors}

The results of the ANOVA examining the effects of distance and sound type on subjective evaluation are shown in Table 4. The estimated marginal means for the cross terms of the factors in each model are shown in Figure 5.

Table 4 shows that the influence of sound type was significant for all factors, indicating that subjective evaluations of sea and traffic differed between all 11 dimensions. Distance exerted a significant impact on most evaluation factors, except for Familiarity and Eventfulness. In addition, the interaction between distance and sound type was significant for all factors (except for Liking and Eventfulness), which shows that in most evaluation factors, the changing trends in sea and traffic differed. 
Table 4 ANOVAs examining differences in the effects of distance and sound type on evaluation factors

\begin{tabular}{|c|c|c|c|c|c|c|}
\hline Factors & Effect & $\begin{array}{c}\text { Type III Sum of } \\
\text { Square }\end{array}$ & $\mathrm{df}$ & Mean Square & $\mathrm{F}$ & Sig. \\
\hline \multirow{3}{*}{ Comfort } & Distance & 107.089 & 2 & 53.544 & 38.251 & $<.001$ \\
\hline & Sound Type & 422.5 & 1 & 422.5 & 301.826 & $<.001$ \\
\hline & Distance * Sound & 18.2 & 2 & 9.1 & 6.501 & .002 \\
\hline \multirow{3}{*}{ Harshness } & Distance & 126.156 & 2 & 63.078 & 46.669 & $<.001$ \\
\hline & Sound Type & 317.344 & 1 & 317.344 & 234.792 & $<.001$ \\
\hline & Distance * Sound & 14.156 & 2 & 7.078 & 5.237 & .006 \\
\hline \multirow{3}{*}{ Pleasantness } & Distance & 60.467 & 2 & 30.233 & 21.052 & $<.001$ \\
\hline & Sound Type & 321.111 & 1 & 321.111 & 223.59 & $<.001$ \\
\hline & Distance * Sound & 10.422 & 2 & 5.211 & 3.629 & .028 \\
\hline \multirow{3}{*}{ Loudness } & Distance & 148.956 & 2 & 74.478 & 46.098 & $<.001$ \\
\hline & Sound Type & 266.944 & 1 & 266.944 & 165.226 & $<.001$ \\
\hline & Distance * Sound & 28.289 & 2 & 14.144 & 8.755 & $<.001$ \\
\hline \multirow{3}{*}{ Liking } & Distance & 102.689 & 2 & 51.344 & 28.256 & $<.001$ \\
\hline & Sound Type & 431.211 & 1 & 431.211 & 237.302 & $<.001$ \\
\hline & Distance * Sound & 2.956 & 2 & 1.478 & 0.813 & .444 \\
\hline \multirow{3}{*}{ Familiarity } & Distance & 1.734 & 2 & 0.867 & 0.45 & .638 \\
\hline & Sound Type & 181.492 & 1 & 181.492 & 94.141 & $<.001$ \\
\hline & Distance * Sound & 8.142 & 2 & 4.071 & 2.112 & .123 \\
\hline \multirow{3}{*}{ Strength } & Distance & 73.837 & 2 & 36.918 & 35.252 & $<.001$ \\
\hline & Sound Type & 27.957 & 1 & 27.957 & 26.695 & $<.001$ \\
\hline & Distance * Sound & 26.784 & 2 & 13.392 & 12.787 & $<.001$ \\
\hline \multirow{3}{*}{ Chaos } & Distance & 103.267 & 2 & 51.633 & 31.888 & $<.001$ \\
\hline & Sound Type & 328.711 & 1 & 328.711 & 203.0077 & $<.001$ \\
\hline & Distance * Sound & 16.422 & 2 & 8.211 & 5.071 & .007 \\
\hline \multirow{3}{*}{ Eventfulness } & Distance & 7.267 & 2 & 3.633 & 1.564 & .211 \\
\hline & Sound Type & 360 & 1 & 360 & 154.986 & $<.001$ \\
\hline & Distance * Sound & 0.867 & 2 & 0.433 & 0.187 & .830 \\
\hline \multirow{3}{*}{ Excitement } & Distance & 39.022 & 2 & 19.511 & 12.581 & $<.001$ \\
\hline & Sound Type & 214.678 & 1 & 214.678 & 138.426 & $<.001$ \\
\hline & Distance $*$ Sound & 9.689 & 2 & 4.844 & 3.124 & .045 \\
\hline \multirow{3}{*}{ Congruency } & Distance & 2.212 & 2 & 1.106 & 0.469 & .626 \\
\hline & Sound Type & 157.717 & 1 & 157.717 & 66.811 & $<.001$ \\
\hline & Distance $*$ Sound & 27.356 & 2 & 13.678 & 5.794 & .003 \\
\hline
\end{tabular}




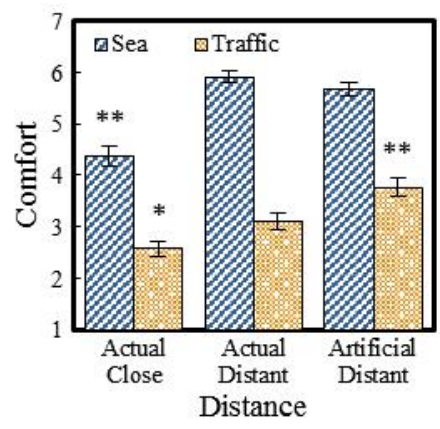

(a) Comfort

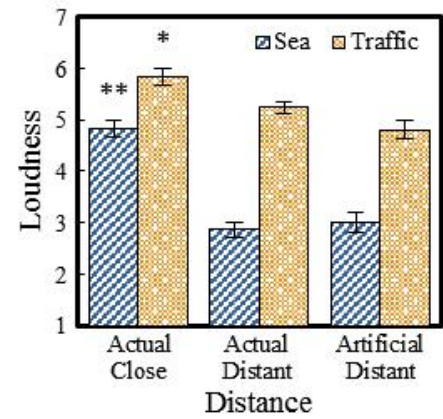

(d) Loudness

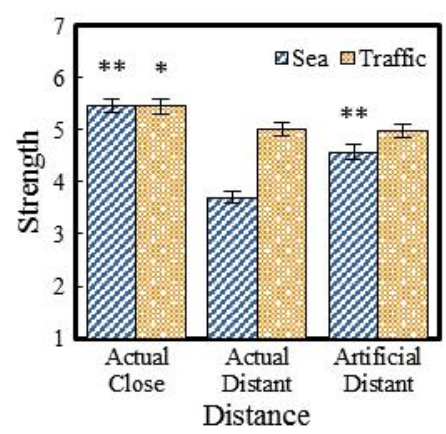

(g) Strength

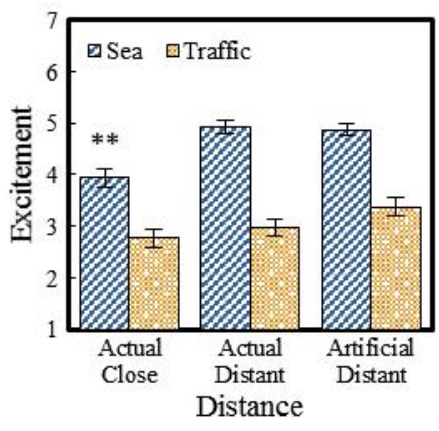

(j) Excitement

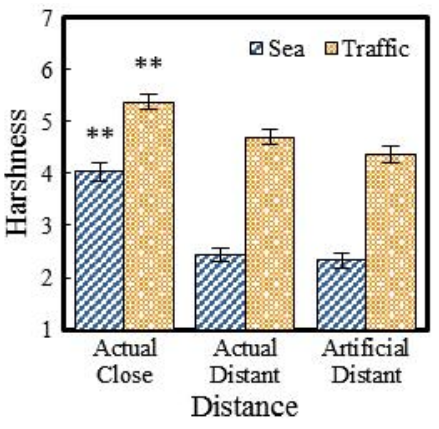

(b) Harshness

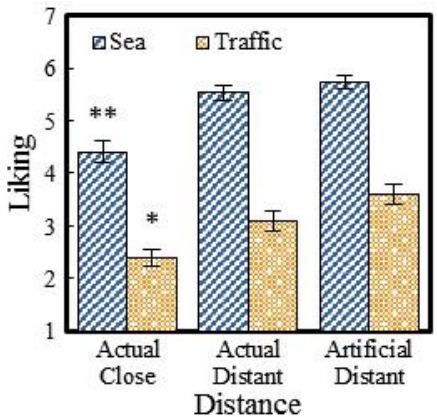

(e) Liking

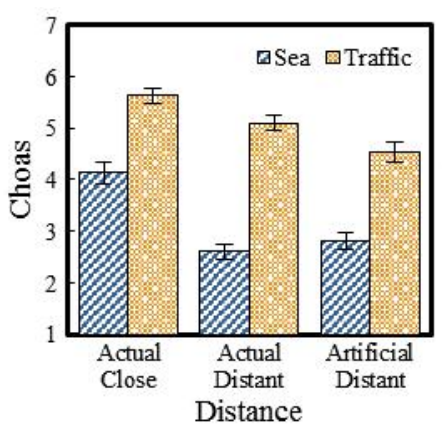

(h) Chaos

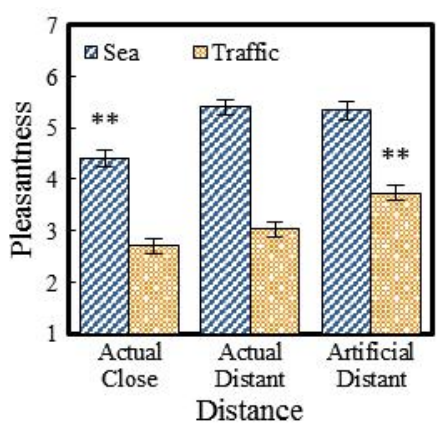

(c) Pleasantness

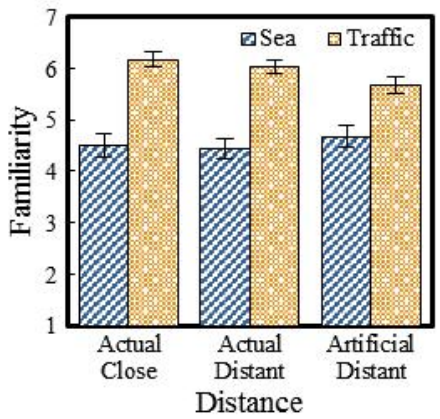

(f) Familiarity

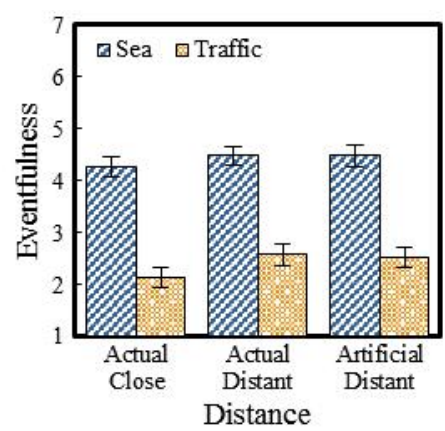

(i) Eventfulness

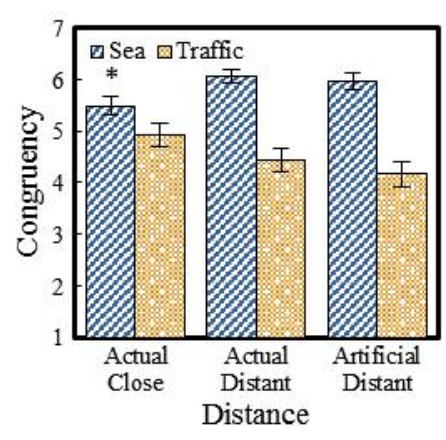

(k) Congruency

Figure 5 Changes in evaluation factors according to distance and sound type

Note: $* * p<.01, * p<.05$

\subsubsection{Effect of actual distance attenuation of sound on subjective evaluation}

The subjective data for the actual distant and actual close group tested via Dunnett tests are shown in Table 5. Due to the significant influence of the interaction in the ANOVAs for subjective evaluation, the post-hoc test was performed with separate data for sea and traffic. 
Table 5 Dunnett tests examining the difference in evaluation factors between the actual close and actual

\begin{tabular}{|c|c|c|c|c|c|c|}
\hline \multirow{2}{*}{ Factor } & \multirow{2}{*}{ Sound type } & \multirow{2}{*}{$\begin{array}{c}\text { Mean } \\
\text { Difference }\end{array}$} & \multirow{2}{*}{ Std. Error } & \multirow{2}{*}{ Sig. } & \multicolumn{2}{|c|}{$95 \%$ Confidence Interval } \\
\hline & & & & & Lower & higher \\
\hline \multirow{2}{*}{ Comfort } & Sea & $-1.53^{*}$ & 0.208 & $<.001$ & -2.00 & -1.07 \\
\hline & Traffic & $-0.53^{*}$ & 0.224 & .034 & -1.03 & -0.03 \\
\hline \multirow{2}{*}{ Harshness } & Sea & $1.60^{*}$ & 0.212 & $<.001$ & 1.13 & 2.07 \\
\hline & Traffic & $0.67^{*}$ & 0.213 & .004 & 0.19 & 1.14 \\
\hline \multirow{2}{*}{ Pleasantness } & Sea & $-1.00^{*}$ & 0.234 & $<.001$ & -1.52 & -0.48 \\
\hline & Traffic & -0.33 & 0.203 & .178 & -0.79 & 0.12 \\
\hline \multirow{2}{*}{ Loudness } & Sea & $1.97^{*}$ & 0.234 & $<.001$ & 1.44 & 2.49 \\
\hline & Traffic & $0.60^{*}$ & 0.230 & .019 & 0.09 & 1.11 \\
\hline \multirow{2}{*}{ Liking } & Sea & $-1.13^{*}$ & 0.232 & $<.001$ & -1.65 & -0.62 \\
\hline & Traffic & $-.070^{*}$ & 0.260 & .015 & -1.28 & -0.12 \\
\hline \multirow{2}{*}{ Familiarity } & Sea & 0.07 & 0.299 & .964 & -0.60 & 0.73 \\
\hline & Traffic & 0.14 & 0.199 & .707 & -0.30 & 0.58 \\
\hline \multirow{2}{*}{ Strength } & Sea & $1.77^{*}$ & 0.187 & $<.001$ & 1.35 & 2.18 \\
\hline & Traffic & $0.45^{*}$ & 0.190 & .036 & 0.03 & 0.87 \\
\hline \multirow{2}{*}{ Chaos } & Sea & $1.53^{*}$ & 0.239 & $<.001$ & 1.00 & 2.07 \\
\hline & Traffic & $0.53^{*}$ & 0.226 & .036 & 0.03 & 1.04 \\
\hline \multirow{2}{*}{ Eventfulness } & Sea & -0.20 & 0.276 & .691 & -0.82 & 0.42 \\
\hline & Traffic & -0.43 & 0.280 & .214 & -1.06 & 0.19 \\
\hline \multirow{2}{*}{ Excitement } & Sea & $-1.00^{*}$ & 0.205 & $<.001$ & -1.46 & -0.54 \\
\hline & Traffic & -0.20 & 0.248 & .634 & -0.75 & 0.35 \\
\hline \multirow{2}{*}{ Congruency } & Sea & $-0.58^{*}$ & 0.228 & .021 & -1.09 & -0.08 \\
\hline & Traffic & 0.50 & 0.326 & .218 & -0.23 & 1.23 \\
\hline
\end{tabular}

Although the results of the ANOVAs (in Table 3) showed that the interaction between distance and sound type is significant in all factors, the results of the post-hoc test showed that the trends of some subjective factors, including Comfort, Harshness, Chaos, Liking, and Strength, were the same for both sea and traffic (see Table 5). Therefore, participants perceived higher Comfort and Liking and lower Harshness, Chaos, and Strength for the actual distant sounds of both sea and traffic. Regarding Pleasantness, Excitement, and Congruency, actual distance attenuation exerted no significant influence on traffic sounds but a significant influence on sea sounds. Participants found the actual distant sound of the sea more pleasant, exciting, and congruent relative to the actual close sound of the sea. Overall, the actual distant sounds appeared to be perceived more positively relative to the actual close sounds, indicating that actual distance attenuation exerted a significant effect on most subjective evaluation factors except 
Zhongzhe Li, Jian Kang, Meihui Ba: Transportation Research Part D: Transport and Environment [https://doi.org/10.1016/j.trd.2020.102538]

Familiarity and Eventfulness.

3.2.3 Effect of artificial distance attenuation of sound on subjective evaluation factors

The results of the Dunnett tests examining the differences between artificial distant group and actual distant group on subjective evaluation are shown in Table 6.

Table 6 Dunnett Tests examining the difference in evaluation factors between the artificial distant and

\begin{tabular}{|c|c|c|c|c|c|c|}
\hline \multirow{2}{*}{ Factor } & \multirow{2}{*}{ Sound type } & \multirow{2}{*}{$\begin{array}{c}\text { Mean } \\
\text { Difference }\end{array}$} & \multirow{2}{*}{ Std. Error } & \multirow{2}{*}{ Sig. } & \multicolumn{2}{|c|}{ 95\% Confidence Interval } \\
\hline & & & & & Lower & higher \\
\hline \multirow{2}{*}{ Comfort } & Sea & -0.23 & 0.208 & .425 & -0.70 & 0.23 \\
\hline & Traffic & $0.67^{*}$ & 0.224 & .006 & 0.17 & 1.17 \\
\hline \multirow{2}{*}{ Harshness } & Sea & -0.10 & 0.212 & .851 & -0.57 & 0.37 \\
\hline & Traffic & -0.33 & 0.213 & .206 & -0.81 & 0.14 \\
\hline \multirow{2}{*}{ Pleasantness } & Sea & -0.07 & 0.234 & .942 & -0.59 & 0.45 \\
\hline & Traffic & $0.70^{*}$ & 0.203 & .001 & 0.25 & 1.15 \\
\hline \multirow{2}{*}{ Loudness } & Sea & 0.13 & 0.234 & .793 & -0.39 & 0.66 \\
\hline & Traffic & -0.43 & 0.230 & .110 & -0.95 & 0.08 \\
\hline \multirow{2}{*}{ Liking } & Sea & 0.20 & 0.232 & .595 & -0.32 & 0.72 \\
\hline & Traffic & 0.50 & 0.260 & .101 & -0.08 & 1.08 \\
\hline \multirow{2}{*}{ Familiarity } & Sea & 0.23 & 0.299 & .652 & -0.43 & 0.90 \\
\hline & Traffic & -0.37 & 0.197 & .115 & -0.81 & 0.07 \\
\hline \multirow{2}{*}{ Strength } & Sea & $0.87^{*}$ & 0.187 & $<.001$ & 0.45 & 1.28 \\
\hline & Traffic & -0.03 & 0.188 & .977 & -0.45 & 0.39 \\
\hline \multirow{2}{*}{ Chaos } & Sea & 0.20 & 0.239 & .613 & -0.33 & 0.73 \\
\hline & Traffic & $-0.57^{*}$ & 0.226 & .024 & -1.07 & -0.06 \\
\hline \multirow{2}{*}{ Eventfulness } & Sea & 0.00 & 0.276 & 1.000 & -0.62 & 0.62 \\
\hline & Traffic & -0.07 & .280 & .959 & -0.69 & 0.56 \\
\hline \multirow{2}{*}{ Excitement } & Sea & -.07 & .205 & .926 & -.52 & .39 \\
\hline & Traffic & .40 & .248 & .189 & -.15 & .95 \\
\hline \multirow{2}{*}{ Congruency } & Sea & -.10 & .226 & .868 & -.60 & .40 \\
\hline & Traffic & -.27 & .326 & .625 & -.99 & .46 \\
\hline
\end{tabular}

As shown in Table 6, there was no significant difference between actual distant and artificial distant sounds in most evaluation factors. Although studies have shown that the frequency spectrum of sound can affect people's comfort and annoyance (Versfeld and Vos, 1997; Nilsson, 2007; Hongisto et al., 2018), only a few subjective factors were affected by spectrum in this experiment. In the traffic condition, Comfort and Pleasantness levels were significantly higher and Chaos levels were significantly lower in 
the artificial distant group relative to the actual distant group. In the sea condition, the differences between actual and artificial attenuation were non-significant for these three factors. Strength levels were significantly higher in the artificial distant group relative to the actual distant group only in the sea condition.

\subsection{Correlation between physiological indicators and subjective evaluation}

As explained by Erfanian et al. (2019), physical and psychological methods are complementary. A very important reason for studying physiological responses in soundscape research is the establishment of a relationship between these physiological results and commonly used psychological approaches. The correlations between physiological indicators and subjective evaluation factors are shown in Table 7.

Table 7 The correlation between physiological indicators and subjective evaluation factors

\begin{tabular}{|c|c|c|c|c|c|c|c|c|c|c|c|}
\hline & Comfort & Harshness & Pleasantness & Loudness & Liking & Familiarity & Strength & Chaos & Eventfulness & Excitement & Congruency \\
\hline HR & $-0.118^{*}$ & 0.057 & -0.033 & 0.054 & -0.010 & -0.058 & -0.001 & 0.016 & -0.019 & -0.070 & 0.028 \\
\hline$\Delta \mathrm{R}$ & 0.020 & 0.043 & 0.009 & $0.116^{*}$ & 0.012 & -0.004 & $0.190^{* *}$ & $0.103^{*}$ & 0.042 & 0.014 & $-0.106^{*}$ \\
\hline SDNN-HRV & -0.048 & 0.030 & -0.006 & 0.045 & -0.057 & 0.012 & -0.006 & 0.047 & 0.077 & $-0.137^{* *}$ & -0.086 \\
\hline HF-HRV & -0.062 & 0.049 & -0.032 & 0.011 & 0.008 & 0.066 & -0.049 & 0.030 & 0.052 & 0.003 & 0.003 \\
\hline$\alpha$-EEG & $0.162^{* *}$ & $-0.127^{*}$ & $0.112^{*}$ & $-0.148^{* *}$ & $0.164^{* *}$ & -0.076 & -0.048 & $-0.183^{* * *}$ & -0.023 & 0.080 & 0.095 \\
\hline B-EEG & $0.162^{* *}$ & $-0.181^{* * *}$ & 0.082 & $-0.176^{* *}$ & $0.173^{* *}$ & -0.037 & $-0.147^{* *}$ & $-0.207^{* *}$ & $-0.113^{*}$ & 0.063 & 0.097 \\
\hline ST & -0.062 & 0.063 & 0.022 & -0.005 & -0.052 & $0.194^{* *}$ & $0.171^{* *}$ & 0.061 & $0.138^{* *}$ & 0.006 & -0.092 \\
\hline $\mathrm{RR}$ & -0.082 & $0.159^{* *}$ & -0.010 & $0.150^{* *}$ & $-0.120^{*}$ & 0.010 & $0.155^{* *}$ & $0.118^{*}$ & 0.086 & -0.009 & -0.023 \\
\hline $\mathrm{RD}$ & 0.094 & $-0.203^{* *}$ & 0.074 & $-0.151^{* *}$ & $0.136^{*}$ & -0.081 & -0.081 & $-0.162^{* *}$ & $-0.127^{*}$ & 0.043 & 0.061 \\
\hline SCL & $-0.216^{* *}$ & $0.215^{* *}$ & $-0.171^{* *}$ & $0.137^{* *}$ & $-0.136^{* *}$ & $0.139^{* *}$ & 0.097 & $0.159^{* *}$ & 0.085 & -0.071 & -0.068 \\
\hline
\end{tabular}

Note: $* * p<.01, * \mathrm{p}<.05$

Table 7 shows the correlations between $\Delta \mathrm{R}, \alpha$-EEG, $\beta$-EEG, RR, RD, and SCL values and subjective evaluation factors. In particular, there was a significant correlation between $\beta$-EEG and eight subjective factors. There have been suggestions that $\beta$-EEG relates to negative emotion (Ray and Cole, 1985; Güntekin and Basar, 2007), but in this experiment, $\beta$-EEG was positively correlated with positive soundscape. This may be because we chose only two scenes, and the sea $\beta$-EEG was higher than that of the traffic. Therefore, it may be the characteristics of sounds that affect $\beta$-EEG (almost all the subjects gave a more positive assessment of sea sound). Regarding subjective evaluation factors, there were correlations between physiological indicators and Comfort, Harshness, Loudness, Liking, Strength, and Chaos levels. Increases in Comfort and Liking levels were associated with increases in $\alpha$-EEG and $\beta$-EEG values and reductions in RR values (only for liking) and SCLs. Harshness, Loudness, and Chaos levels showed the opposite effects on these physiological indicators. This indicates that positive evaluation was often related to a relaxed state, and physical and psychological trends were synchronised. However, all the coefficients for the correlations shown in Table 7 were exceptionally low (mostly between 0.1 and 
0.2 ), showing very weak correlations. Therefore, it is both difficult to speculate on subjective evaluations using physiological indicators and estimate changes in physiological indicators using subjective evaluation data. In an ongoing follow-up study, examining a wider range of soundscape stimuli could help establish a more comprehensive relationships between physical and psychological factors.

\section{Discussion}

\subsection{The difference between sea and traffic}

Table 1 shows that the effect of sound type on physiological indicators was non-significant, with the exception of $\alpha$-EEG, $\beta$-EEG, RD, and SCL values. As shown in Figure 2, participants in the sea condition showed higher $\alpha$-EEG, $\beta$-EEG, and RD values and lower SCLs relative to those in the traffic condition. According to these four indicators, participants appeared to relax more with sea sounds, relative to traffic sounds, which was most obvious in the $\alpha$-EEG values (see Figure 4e), which were higher with the sea sound relative to those recorded in a resting state, while those with the traffic sound were lower than baseline values. This is consistent with a previous study finding that showed sea sound can increase $\alpha$-EEG and decrease RD, and SCL, compared to other sound environments (Li and Kang, 2019). In addition, various studies have repeatedly shown that natural sounds such as sea waves and birdsong have better physiological restorative effects (Ratcliffe et al., 2013; Ma and Shu, 2018). Although some physiological indicators showed differences between the two scenes, the influences of sound type on the indicators were much weaker than that of distance (in Table 1, the F values of most indicators under Distance were much higher than those under Sound Type, except for HF-HRV, $\alpha$-EEG, and RD). The reason for this finding could be that there was a strong similarity in the acoustic characteristics of sea and traffic sounds. Most indicators may not be able to detect the spectral difference between the two sounds, as the spectrum change caused by distance is larger than that caused by sound type in some aspects. Therefore, the physiological indicators (except for HF-HRV, $\alpha$-EEG and RD) may be more sensitive to the physical characteristics of sound, rather than to the sound type. The reason for this finding could be that there was a strong similarity in the acoustic characteristics of sea and traffic sounds, which reduced the strength of the physiological distinction between them. In contrast, the change in sound spectrum values according to distance was greater relative to that according to sound type.

The difference in subjective evaluation factors between sea and traffic sounds was highly significant. As shown in Figure 5, for all factors, the difference between the two sounds was considerable, and the influence of sound type on subjective evaluation was much stronger relative to that of distance. The sea sound was affected more strongly by actual distance attenuation relative to the traffic sound, and the difference in subjective evaluations between the actual close and actual distant sea sounds was generally greater relative to that for traffic sounds, indicating that participants were more sensitive to sound source distance in the sea condition. However, with respect to artificial distance attenuation, participants' sensitivity to traffic sounds was greater than that for sea sounds (in Table 6, the mean difference in traffic sounds was greater and the significance of the traffic sounds was higher, relative to those for the sea 
sounds). This could have occurred because people are more familiar with traffic noises. At the end of the experiment, many participants in the artificial distant group reported being clearly aware that the traffic noise they heard was very close to them, that the vehicles sounded as though they had passed right in front of them, but the sound was not very loud. However, only a few participants in this group realised that the source of sea sound was very close to them. Therefore, the familiarity of the sound sources could explain the difference between subjective sensitivity to sea and traffic sounds. These results show that the influence of SPL on subjective evaluation is much greater than that of spectrum, and that people may be more sensitive to the noise sources that they are familiar with. In addition, visual factors may have a greater impact on subjective evaluation, because vision plays a more a leading role among the senses (Carles et al., 1992; Godfroy-Cooper et al., 2015). People have completely different subjective feelings about the sea sound and traffic sound which are similar in hearing, which is probably mainly due to the influence of visual factors on the scenes.

\subsection{Sensitivity of physiological indicators and subjective evaluation factors}

Which is more sensitive to soundscapes, physiological indicators or subjective evaluation factors? According to the current data, the sensitivity of physiological indicators and subjective evaluation factors were reflected in different respects. It was clear that subjective evaluation factors were more sensitive to sound type. As shown in Figure 5, the difference between the sea and traffic sounds was considerable for all evaluation factors. However, similar significant differences in physiological indicators were not observed. Actual distance attenuation exerted a stronger impact on subjective evaluation factors relative to physiological indicators. Differences between the actual close and actual distant groups were observed from only some physiological indicators, including HR, $\triangle \mathrm{R}$, SDNN-HRV, RR, and SCL values. The effects of artificial distance attenuation on subjective evaluation factors was very weak, but the difference could still be observed in other physiological indicators including $\Delta \mathrm{R}, \alpha$-EEG, $\beta$-EEG, and SCL values.

Therefore, participants were more subjectively sensitive to sound type, and different physiological indicators showed different degrees of sensitivity to distance. This indicates that physiological indicators tended to be more sensitive to the physical characteristics of sound, while subjective evaluation factors were based on the meanings underlying the sounds. People's perception of sound is not only determined by the bottom-up signals, but also modulated by the change of individual states (top-down signal) (Huang and Elhilali, 2017; Kaya and Elhilali, 2017). In the physiological data, the subjects listened to the sound passively, their attention was mainly determined by the characteristics of the sound and visual stimuli. However, in the subjective evaluation, perception of sound was further influenced by top-down factors, which mainly depends on the subjects' psychological state and their understanding of the sound. In addition, the perception in the experiment was properly integrated under different modes (visual and auditory) input. The multi-sensory processing is dynamically adjusted, leading to a unique and subjective perceptual experience (Choi et al., 2018). Finally, it is important to remark that the perception of attention (salience) by sound spectrum and the influence of audio-visual interaction on auditory perception are worthy of further research. 


\section{Conclusions}

In the current soundscape study, the effects of distance on physiological indicators and subjective evaluation factors were examined through three types of distance of sea and traffic sounds in a laboratory. The main conclusions of the study were as follows.

(1) Actual distance attenuation (with different SPLs) affected some physiological indicators: people showed higher HR, $\triangle \mathrm{R}, \mathrm{SDNN}-\mathrm{HRV}, \mathrm{RR}$, and SCL values when close to the sound source. In addition, artificial distance attenuation (with the same SPL) affected some physiological indicators: $\Delta \mathrm{R}, \alpha$-EEG, and $\beta$-EEG values with actual distant sounds were lower and SCLs were higher relative to those with artificial distant sounds.

(2) Actual distance attenuation affected most subjective evaluation factors (except for Familiarity and Excitement). People perceived high levels of Comfort and Liking and low levels of Harshness, Chaos, and Strength with actual distant sounds. The influence of artificial distance attenuation on subjective evaluation values was relatively weak: with traffic sounds, Comfort and Pleasantness levels with artificial distant sound were higher and Chaos levels were lower relative to those with actual distant sound; with sea sounds, only Strength levels were lower with actual distant sound, relative to artificial distant sound.

Further, once the sound level was reduced, the influence of spectrum on subjective evaluation was not significant. Subjective evaluation factors were most sensitive to sound type, and physiological indicators were most sensitive to the characteristics of sounds. In addition, there were weak correlations between physiological indicators and subjective factors.

Although the current study was based on outdoor environments, the results regarding sea and traffic sounds represent other playback sound source functions that could be installed in indoor public spaces. In future laboratory experiments, when it is necessary to restore the sound environment, especially when focusing on subjective perception of sound, the real recording method should be used in place of artificial adjustment of parameters such as SPL and loudness. Although in this experiment, most of the subjective factors were not sensitive enough to detect the spectrum difference caused by the attenuation mode (this may be due to the fact that the differences between different conditions in the experiment was relatively small), some physiological indicators could detect differences. These differences, which cannot be examined via questionnaires, are meaningful. The sensitivity and threshold of subjective factors to spectrum changes are worthy of further study. In addition to controlling the SPL in the environment, we also need to consider more about low-frequency sounds, to avoid their impact on human physiology. The effects of distance and spectrum of sound on behaviour, sleep, and other health-related factors are worth studying.

\section{Acknowledgements}

The authors would like to express sincere gratitude to all participants in the experiment. 


\section{Declaration of interest}

None

\section{Funding}

This study was supported by the National Natural Science Foundation of China [grant number: 51778169].

\section{References}

Aletta, F., Kang, J., Axelsson, Ö., 2016. Soundscape descriptors and a conceptual framework for developing predictive soundscape models. Landsc. Urban Plan. 149, 65-74.

https://doi.org/10.1016/j.landurbplan.2016.02.001.

Alvarsson, J.J., Wiens, S., Nilsson, M.E., 2010. Stress recovery during exposure to nature sound and environmental noise. Int. J. Environ. Res. Public Health. 7(3), 1036-1046.

https://doi.org/10.3390/ijerph7031036.

Axelsson, Ö., Nilsson, M.E., Berglund, B., 2010. A principal components model of soundscape perception. J. Acoust. Soc. Am. 128(5), 2836-2846. https://doi.org/10.1121/1.3493436.

Ba, M., Kang, J., 2019a. A laboratory study of the sound-odour interaction in urban environments. Build. Environ. 147, 314-326. https://doi.org/10.1016/i.buildenv.2018.10.019.

Ba, M., Kang, J., 2019b. Effect of a fragrant tree on the perception of traffic noise. Build. Environ. 156, 147-155. https://doi.org/10.1016/i.buildenv.2019.04.022.

Basner, M., Müller, U., Griefahn, B., 2010. Practical guidance for risk assessment of traffic noise effects on sleep. Appl. Acoust. 71(6), 518-522. https://doi.org/10.1016/i.apacoust.2010.01.002.

Bradley, M.M., Codispoti, M., Cuthbert, B.N., Lang, P.J., 2001. Emotion and Motivation I: Defensive and Appetitive Reactions in Picture Processing. Emotion 1(3), 276-298.

https://doi.org/10.1037/1528-3542.1.3.276.

Carles, J., Bernáldez, F., De Lucio, J., 1992. Audiovisual interactions and soundscape preferences. Landsc. Res. 17, 52-56. https://doi.org/10.1080/01426399208706361

Cerwén, G., Pedersen, E., Pálsdóttir, A.M., 2016. The role of soundscape in nature-based rehabilitation: A patient perspective. Int. J. Environ. Res. Public Health 13(12). https://doi.org/10.3390/ijerph13121229. 
Choi, I., Lee, J.Y., Lee, S.H., 2018. Bottom-up and top-down modulation of multisensory integration. Curr. Opin. Neurobiol. 52, 115-122. https://doi.org/10.1016/j.conb.2018.05.002

Coensel, B. De, Vanwetswinkel, S., Botteldooren, D., 2011. Effects of natural sounds on the perception of road traffic noise. J. Acoust. Soc. Am. 129(4), EL148-EL153. https://doi.org/10.1121/1.3567073.

De Gelder, B., Bertelson, P., 2003. Multisensory integration, perception and ecological validity. Trends Cogn. Sci. 7(10), 460-467. https://doi.org/10.1016/j.tics.2003.08.014.

Erfanian, M., Mitchell, A.J., Kang, J., Aletta, F., 2019. The psychophysiological implications of soundscape: A systematic review of empirical literature and a research agenda. Int. J. Environ. Res. Public Health 16(19), 1-20. https://doi.org/10.3390/ijerph16193533.

Fachner, J., Gold, C., Erkkilä, J., 2013. Music therapy modulates fronto-temporal activity in rest-EEG in depressed clients. Brain Topogr. 26, 338-354. https://doi.org/10.1007/s10548-012-0254-x

Fernández, T., Harmony, T., Rodríguez, M., Bernal, J., Silva, J., Reyes, A., Marosi, E., 1995. EEG activation patterns during the performance of tasks involving different components of mental calculation. Electroencephalogr. Clin. Neurophysiol. 94, 175-182. https://doi.org/10.1016/0013-4694(94)00262-J

Finegold, L.S., Harris, C.S., von Gierke, H.E., 1994. Community annoyance and sleep disturbance: Updated criteria for assessing the impacts of general transportation noise on people. Noise Control Eng. J. 42(1), 25-30. https://doi.org/10.3397/1.2827857.

Galbrun, L., Ali, T.T., 2013. Acoustical and perceptual assessment of water sounds and their use over road traffic noise. J. Acoust. Soc. Am. 133(1), 227-237. https://doi.org/10.1121/1.4770242.

Godfroy-Cooper, M., Sandor, P.M.B., Miller, J.D., Welch, R.B., 2015. The interaction of vision and audition in two-dimensional space. Front. Neurosci. 9. https://doi.org/10.3389/fnins.2015.00311

Griffiths, I.D., Langdon, F.J., 1968. Subjective response to road traffic noise. J. Sound Vib. 8(1), 16-32. https://doi.org/10.1016/0022-460X(68)90191-0

Güntekin, B., Basar, E., 2007. Emotional face expressions are differentiated with brain oscillations. Int. J. Psychophysiol. 64, 91-100. https://doi.org/10.1016/j.ijpsycho.2006.07.003

Huang, N., Elhilali, M., 2017. Auditory salience using natural soundscapes. J. Acoust. Soc. Am. 141, 2163-2176. https://doi.org/10.1121/1.4979055 
Hermida Cadena, L.F., Lobo Soares, A.C., Pavón, I., Bento Coelho, J.L., 2017. Assessing soundscape: Comparison between in situ and laboratory methodologies. Noise Mapp. 4(1), 57-66. https://doi.org/10.1515/noise-2017-0004.

Hong, J.Y., He, J., Lam, B., Gupta, R., Gan, W.S., 2017. Spatial audio for soundscape design: Recording and reproduction. Appl. Sci. 7(6). https://doi.org/10.3390/app7060627.

Hongisto, V., Oliva, D., Rekola, L., 2018. Subjective and objective rating of the sound insulation of residential building façades against road traffic noise. J. Acoust. Soc. Am. 144(2), 1100-1112. https://doi.org/10.1121/1.5051647.

Hume, K., Ahtamad, M., 2013. Physiological responses to and subjective estimates of soundscape elements. Appl. Acoust. 74(2), 275-281. https://doi.org/10.1016/j.apacoust.2011.10.009.

Hunter, M.D., Eickhoff, S.B., Pheasant, R.J., Douglas, M.J., Watts, G.R., Farrow, T.F.D., Hyland, D., Kang, J., Wilkinson, I.D., Horoshenkov, K. V., Woodruff, P.W.R., 2010. The state of tranquility: Subjective perception is shaped by contextual modulation of auditory connectivity. Neuroimage 53(2), 611-618. https://doi.org/10.1016/j.neuroimage.2010.06.053.

Irwin, A., Hall, D.A., Peters, A., Plack, C.J., 2011. Listening to urban soundscapes: Physiological validity of perceptual dimensions. Psychophysiology 48(2), 258-268.

https://doi.org/10.1111/i.1469-8986.2010.01051.x.

Jeon, J.Y., Lee, P.J., You, J., Kang, J., 2010. Perceptual assessment of quality of urban soundscapes with combined noise sources and water sounds. J. Acoust. Soc. Am. 127(3), 1357-1366. https://doi.org/10.1121/1.3298437.

Joynt, J.L.R., Kang, J., 2010. The influence of preconceptions on perceived sound reduction by environmental noise barriers. Sci. Total Environ. 408(20), 4368-4375. https://doi.org/10.1016/i.scitotenv.2010.04.020.

Kang, J., Aletta, F., Gjestland, T.T., Brown, L.A., Botteldooren, D., Schulte-Fortkamp, B., Lercher, P., van Kamp, I., Genuit, K., Fiebig, A., Bento Coelho, J.L., Maffei, L., Lavia, L., 2016. Ten questions on the soundscapes of the built environment. Build. Environ. 108, 284-294.

https://doi.org/10.1016/i.buildenv.2016.08.011.

Kang, J., Zhang, M., 2010. Semantic differential analysis of the soundscape in urban open public spaces. Build. Environ. 45(1), 150-157. https://doi.org/10.1016/j.buildenv.2009.05.014. 
Kaya, E.M., Elhilali, M., 2017. Modelling auditory attention. Philos. Trans. R. Soc. B Biol. Sci. https://doi.org/10.1098/rstb.2016.0101

Klimesch, W., 1999. EEG alpha and theta oscillations reflect cognitive and memory performance: A review and analysis. Brain Res. Rev. https://doi.org/10.1016/S0165-0173(98)00056-3

Kreibig, S.D., 2010. Autonomic nervous system activity in emotion: A review. Biol. Psychol. 84, 394-421. https://doi.org/10.1016/i.biopsycho.2010.03.010

Li, Z., Kang, J., 2019. Sensitivity analysis of changes in human physiological indicators observed in soundscapes. Landsc. Urban Plan. 190. https://doi.org/10.1016/j.landurbplan.2019.103593.

Lindquist, M., Lange, E., Kang, J., 2016. From 3D landscape visualization to environmental simulation: The contribution of sound to the perception of virtual environments. Landsc. Urban Plan. 148, 216-231. https://doi.org/10.1016/i.landurbplan.2015.12.017.

Ma, H., Shu, S., 2018. An experimental study: The restorative effect of soundscape elements in a simulated open-plan office. Acta Acust. united with Acust. 104, 106-115.

https://doi.org/10.3813/AAA.919150

McCorry, L.K., 2007. Physiology of the autonomic nervous system. Am. J. Pharm. Educ. 71. https://doi.org/10.5688/aj710478

Medvedev, O., Shepherd, D., Hautus, M.J., 2015. The restorative potential of soundscapes: A physiological investigation. Appl. Acoust. 96, 20-26. https://doi.org/10.1016/j.apacoust.2015.03.004.

Miedema, H.M.E., Vos, H., 1998. Exposure-response relationships for transportation noise. J. Acoust. Soc. Am. 104(6), 3432-3445. https://doi.org/10.1121/1.423927.

Monrad, M., Sajadieh, A., Christensen, J.S., Ketzel, M., Raaschou-Nielsen, O., Tjønneland, A., Overvad, K., Loft, S., Sørensen, M., 2016. Residential exposure to traffic noise and risk of incident atrial fibrillation: A cohort study. Environ. Int. 92-93, 457-463. https://doi.org/10.1016/i.envint.2016.04.039.

Muzet, A., 2007. Environmental noise, sleep and health. Sleep Med. Rev. 11(2), 135-142. https://doi.org/10.1016/j.smrv.2006.09.001. 
Nilsson, M.E., 2007. A-weighted sound pressure level as an indicator of short-term loudness or annoyance of road-traffic sound. J. Sound Vib. 302(1-2), 197-207. https://doi.org/10.1016/i.jsv.2006.11.010.

Nilsson, M.E., Alvarsson, J., Rådsten-Ekman, M., Bolin, K., 2010. Auditory masking of wanted and unwanted sounds in a city park. Noise Control Eng. J. 58(5), 524-531. https://doi.org/10.3397/1.3484182.

Prinsloo, G.E., Rauch, H.G.L., Karpul, D., Derman, W.E., 2013. The effect of a single session of short duration heart rate variability biofeedback on EEG: A pilot study. Appl. Psychophysiol. Biofeedback 38, 45-56. https://doi.org/10.1007/s10484-012-9207-0

Ratcliffe, E., Gatersleben, B., Sowden, P.T., 2013. Bird sounds and their contributions to perceived attention restoration and stress recovery. J. Environ. Psychol. 36, 221-228.

https://doi.org/10.1016/i.jenvp.2013.08.004

Ray, W.J., Cole, H.W., 1985. EEG alpha activity reflects attentional demands, and beta activity reflects emotional and cognitive processes. Science. 228, 750-752. https://doi.org/10.1126/science.3992243

Roswall, N., Raaschou-Nielsen, O., Jensen, S.S., Tjønneland, A., Sørensen, M., 2018. Long-term exposure to residential railway and road traffic noise and risk for diabetes in a Danish cohort. Environ. Res. 160, 292-297. https://doi.org/10.1016/i.envres.2017.10.008.

Seidler, A., Wagner, M., Schubert, M., Dröge, P., Römer, K., Pons-Kühnemann, J., Swart, E., Zeeb, H., Hegewald, J., 2016. Aircraft, road and railway traffic noise as risk factors for heart failure and hypertensive heart disease-A case-control study based on secondary data. Int. J. Hyg. Environ. Health 219(8), 749-758. https://doi.org/10.1016/i.ijheh.2016.09.012.

Torresin, S., Albatici, R., Aletta, F., Babich, F., Kang, J., 2019. Assessment methods and factors determining positive indoor soundscapes in residential buildings: A systematic review. Sustain. 11(19), 5290. https://doi.org/10.3390/su11195290.

Vallet, M., Gagneux, J.M., Blanchet, V., Favre, B., Labiale, G., 1983. Long term sleep disturbance due to traffic noise. J. Sound Vib. 90(2), 173-191. https://doi.org/10.1016/0022-460X(83)90527-8.

Versfeld, N.J., Vos, J., 1997. Annoyance caused by sounds of wheeled and tracked vehicles. J. Acoust. Soc. Am. 101(5), 2677-2685. https://doi.org/10.1121/1.418556.

Watts, G.R., Pheasant, R.J., Horoshenkov, K. V., Ragonesi, L., 2009. Measurement and subjective assessment of water generated sounds. Acta Acust. united with Acust. 95(6), 1032-1039. 
Zhongzhe Li, Jian Kang, Meihui Ba: Transportation Research Part D: Transport and Environment

[https://doi.org/10.1016/j.trd.2020.102538]

https://doi.org/10.3813/AAA.918235.

Zhang, X., Ba, M., Kang, J., Meng, Q., 2018. Effect of soundscape dimensions on acoustic comfort in urban open public spaces. Appl. Acoust. 133, 73-81. https://doi.org/10.1016/j.apacoust.2017.11.024.

Zhao, Y., Sun, Q., Chen, G., Yang, J., 2018. Hearing emotional sounds: category representation in the human amygdala. Soc. Neurosci. 13, 117-128. https://doi.org/10.1080/17470919.2016.1267040 